\title{
OPTIMIZATION OF 3D PRINTING PARAMETERS ON SURFACE ROUGHNESS BY
}

\section{TAGUCHI METHOD}

\author{
SEELAM RAVINDER ${ }^{1} \&$ CHINTIREDDY SHARATH REDDY ${ }^{2}$ \\ ${ }^{I}$ Department of Mechanical Engineering,JNTUH College of Engineering Sultanpur, Sangareddy, Telangana, India \\ ${ }^{2}$ Department of Mechanical Engineering, Chaitanya Bharathi Institute of Technology (A), Hyderabad, Telangana, India
}

\begin{abstract}
Fused Deposition Modeling (FDM) is a type of rapid prototyping technique used in manufacturing prototypes among the additive manufacturing technologies.3D printing is a type of FDM where the prototypes are made layer by layer addition of molten filament material.3D printing directly converts the $3 D-C A D$ data into prototypes(model). Our present involves studying the parameters which affect the surface roughness of $3 D$ printed material are optimized. The material used for deposition is Polylactic Acid (PLA), a common thermoplastic polymer. The parameters like infill density, print speed, printing temperature and wall thickness are varied according to the design of experiments. Taguchi method was adopted to design the experiments and an orthogonal array of $L 9(34)$ is designated and performed to find out the optimal values to minimize the surface roughness of $3 D$ printed PLA material. The surface roughness test is conducted on each specimen as per standards.

KEYWORDS: Fused Deposition Modeling (FDM), Additive Manufacturing, Poly Lactic Acid (PLA), Taguchi Method \& Surface Roughness Test
\end{abstract}

Received: Jun 09, 2020; Accepted: Jun 29, 2020; Published: Sep 21, 2020; Paper Id.: IJMPERDJUN20201372

\section{INTRODUCTION}

In the manufacturing zone, Additive manufacturing a new technology has been proven to be a promising method for adopting in rapid prototyping. This technology substantially has evolved and improved into a useful tool for many fields like in researcher, designing, manufacturing sector. Collaborating different fields in single package molded 3D printer which includes Design, manufacturing, electronics, materials, and business. The classic difference between traditional manufacturing method and 3D printing is, the 3D printer involves additive approach but mostly traditional manufacturing processes involve subtractive approach which includes a combination of cutting, bending, grinding, forging, molding, welding and assembling operations.

Additive Manufacturing (AM), usually known as 3D printing, is defined as the "joining of materials to make an object from 3D model data, generally by layer upon layer, as opposed to formative manufacturing methodologies" according to International Organization for Standardization (ISO)/American Society for Testing and Materials(ASTM) 52900:2015 standard [1].Based on standards, AM processes is classified into seven classes: Binder-Jetting, Material's Extrusion, Powder Bed Fusion, Directed Energy Deposition, Material-Jetting, Sheet Lamination and Vat Photo Polymerization.

\section{FUSED DEPOSITION MODELING}

Fused Deposition Modeling (FDM) or Fused Filament Fabrication (FFF) is a3D printing material-extrusion process which employs, a continuous distributing of filament of a thermoplastic material which is encouraged from alarge 
and moving loop with an in situ -heater in printer extruder head. Molten material is pumped out of the print head's nozzle which gets deposited on the growing work piece. The head movement is under computer control, to define the printed shape. Usually the head moves in layers and in two dimensions to deposit one horizontal plane at a time, before moving marginally upwards to begin a new slice. The speed of the extruder head can be controlled, to start and stop the deposition and to form an interrupted plane short of stringing or dribbling among the sections[2].

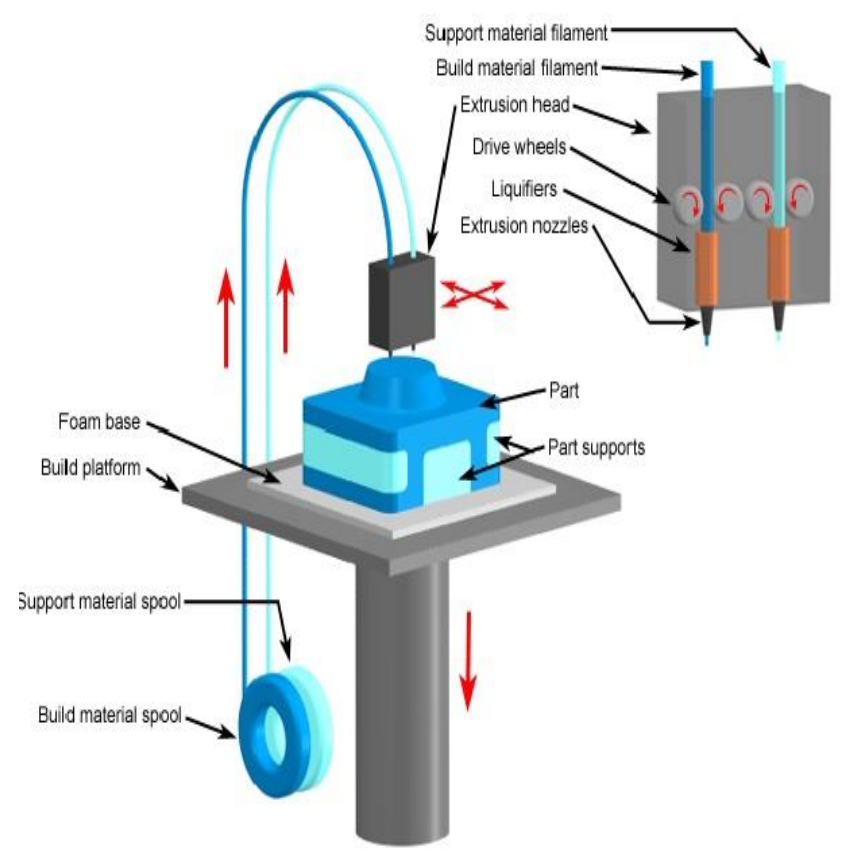

Figure 1: Fused Deposition Modeling.

3D printing works on three main steps:

- The first step is designing an object, you design a 3D file of the object that need to be printed[3].This 3D file are created using CAD software's, with a 3D scanner or designed in modeling software. Once you have checked that your $3 \mathrm{D}$ file to be printed is ready, we can proceed to the second step.

- The second step is the actual printing process. First, you need to choose which material with desirable properties for the object. Large variety of materials are used in 3D printing which includes plastics, ceramics, resins, metals, sand, textiles, biomaterials, glass, food and even lunar dust.

- The third step is the finishing process. This step necessitates specific skills for producing final object. When the object is first printed, regularly it cannot be directly delivered or used until it has tobe sanded, lacquered or painted to complete it as intended. 


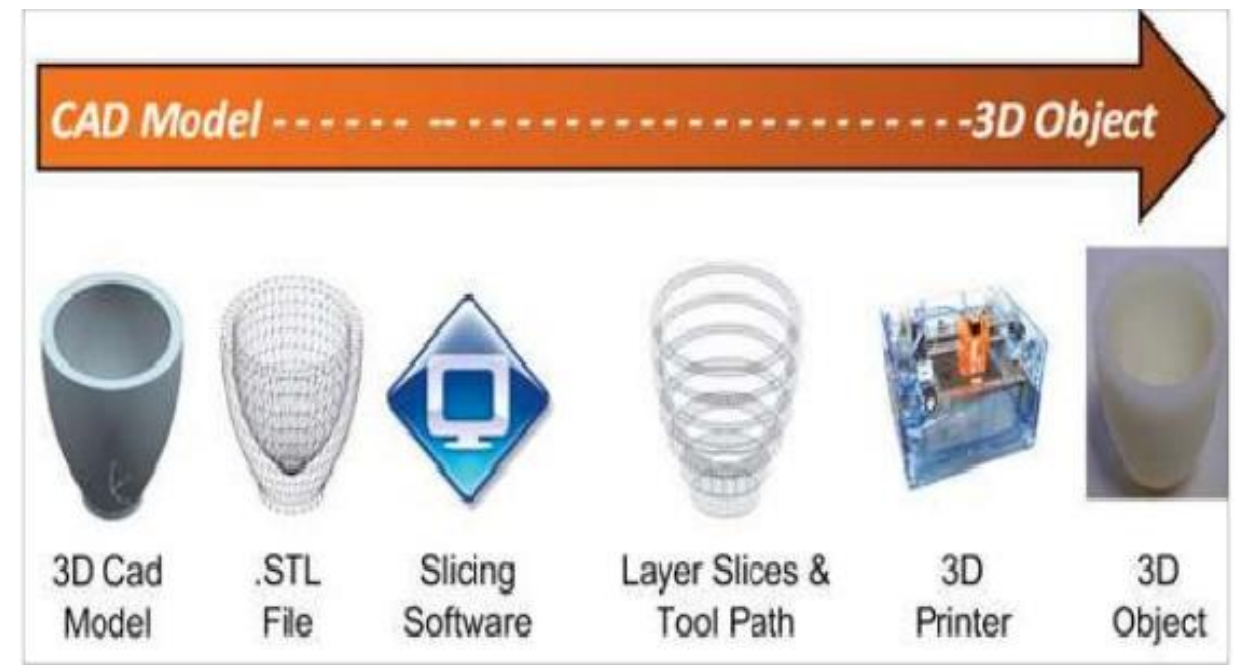

Figure 2: 3D Printing Process.

Parameters of 3D Printing:

- Infill density: Infill is a value which is represented in percentages that shows how much a solid model should be filled-in with material, when printed. Normally, except if you need maximum strength/stiffness you would not have to go for extreme fill of a 3D model, particularly in the event if you want to save on material costs, model weight and want to get the print quicker.

- Number of shells: Number of Shells (Outline/Perimeter Shells) is a value that sets the number of outlines to be printed on each layer of the object more the shells the stronger the printed object is, hence setting high number of basic shells make the printed part with denser outside walls.

- Layer Height: Layer Height is the main parameter which reflects the print quality, it sets the thickness of each layer to be printed. Lower the number, the thinner each layer so best of quality 3D prints can be deposited. However decreasing the layer thickness means more layers are needed to be printed and the time required for the 3D printing will significantly increase[4].

- Extruder Temperature: Extruder Temperature is the temperature at which the extruder requires while performing printing. The extruder temperature depends on the material used, the value of $230^{\circ} \mathrm{C}$ is taken for printing using PLA/ABS filaments was per the standards and however flexible filaments typically require lower extruder temperature.

- Printing Speed: Printing Speed (Speed while extruding) is the speed at which the printing head moves while extruding the filament to make the physical representation of the 3D model[5]. Depending upon the model and the filament, we can optimize the printing speed to obtain excellent quality prints.

- Movement Speed: Movement Speed (Speed while Traveling) is the speed that the printing head moves when not extruding filament, the speed can normally be quicker than while extruding the filament and its generallytwice the speed while printing the object.

\section{Material used in FDM}

Poly-Lactic-Acid (PLA), a thermoplastic polymer materials which is synthesized from corn, starch and sugarcane, possessing 
a low melting point is selected, which is a suitable material for depositing complicate objects with an easeand resulting in smooth prints .Hence it's highly recommended for prototypes, probes and models[6].

Characteristics of PLA are:

- High tensile strength

- Good surface quality

- $\quad$ Ease to work at high print speeds

- Permits the creation of high-resolution parts and intricate objects

- $\quad$ Perfect for models and prototypes that require aesthetics

- Good for lost casting methods to produce metal parts

Table 1: Specifications of PLA - $\left(\mathrm{C}_{3} \mathrm{H}_{4} \mathrm{O}_{2}\right)_{n}$

\begin{tabular}{|l|c|}
\hline \multicolumn{1}{|c|}{ Specifications } & PLA \\
\hline Printing temperature $\left({ }^{\circ} \mathrm{C}\right)$ & $190-230$ \\
\hline Bed temperature $\left({ }^{\circ} \mathrm{C}\right)$ & 70 \\
\hline Tensile yield strength $(\mathrm{MPa})$ & 60 \\
\hline Density $\left(\mathrm{g} / \mathrm{cm}^{3}\right)$ & 1.24 \\
\hline Tensile Modulus $(\mathrm{GPa})$ & 3.5 \\
\hline Tensile Elongation $(\%)$ & 6 \\
\hline Biodegradable & Yes \\
\hline Glass transition temperature $\left({ }^{\circ} \mathrm{C}\right)$ & 60 \\
\hline
\end{tabular}

\section{SPECIFICATIONS OF 3D PRINTER}

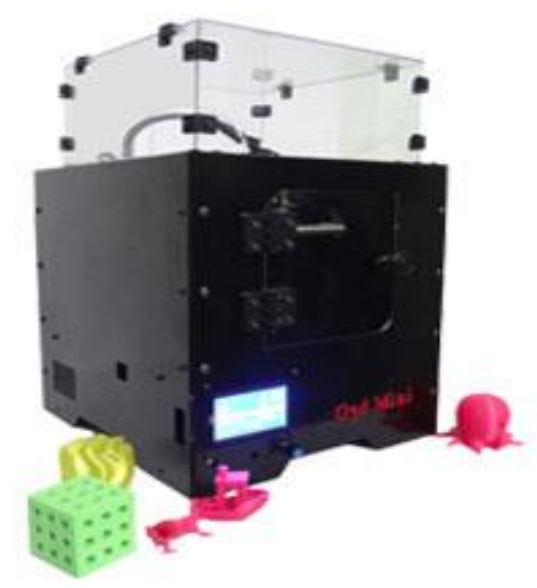

Figure 3: 3D Printer (G3d Mini Instrument).

- Technology: Fused Deposition Modeling (FDM)

- Instrument: $\mathrm{G}_{3} \mathrm{~d}$ Mini

- $\quad$ Print Head: Removable, Exchangeable

- Build Volume:100 x 100 x 100 
- $\quad$ Filament Diameter: $1.75 \mathrm{~mm}$

- Layer Resolution: $0.4 \mathrm{~mm}$ Nozzle 300 to 50 microns

- $\quad$ XYZ Accuracy : 8, 8, 8 microns

- Movement Speed: Up to $150 \mathrm{~mm} / \mathrm{s}$

- Extrusion Speed: $3 \mathrm{~mm}^{3} / \mathrm{s}$

- Build Plate:4mm Acrylic

- $\quad$ Material: PLA, ABS

- $\quad$ Nozzle Diameter: $0.2,0.3,0.4 \mathrm{~mm}$

- $\quad$ Nozzle Temperature: $170-240\left({ }^{\circ} \mathrm{C}\right)$

- $\quad$ Nozzle heat up time: 50 s

\section{TAGUCHI METHOD}

The Taguchi method was developed by Genichi Taguchi, encompasses reduction of variation in a process through a robust design of experimentation and produce high quality product at low cost to the manufacturer. The experimental design proposed by Taguchi involves using an orthogonal array to organize the parameters which affect the process and the dimensions at which they are varied [7]. Instead of testing all possible combinations like the factorial design, the Taguchi method tests pairs the combinations. This allows the collection of the essential data to determine what factors affects the product quality with a minimum amount of experimentation which helps to save time and resources.

\subsection{Taguchi Orthogonal Array Design - L9 (3*4):}

Taguchi Orthogonal Array (OA) design is general fractional-factorial type model. The arrays are adjusted to ensure that all levels and all factors are considered equally. For this reason, the factors can be evaluated independently despite the fractionality of the design. Table. 2 shows the Taguchi orthogonal array selector which shows the orthogonal array for the parameters and levels. For three parameters and three levels L 9 orthogonal arrays was selected from the array selector [8].

Table 2: Considered Parameters and Levels for Experimentation

\begin{tabular}{|l|c|c|c|}
\hline \multicolumn{1}{|c|}{ Parameters } & Level 1 & Level 2 & Level 3 \\
\hline Wall Thickness (mm) & 0.8 & 1.2 & 1.6 \\
\hline Infill Density $(\%)$ & 0 & 50 & 100 \\
\hline Print Speed $(\%)$ & 20 & 60 & 100 \\
\hline Temperature $\left({ }^{\circ} \mathrm{C}\right)$ & 190 & 210 & 230 \\
\hline
\end{tabular}


Table 3: S/N Ratio Values for Surface Roughness

\begin{tabular}{|c|c|c|c|c|c|c|}
\hline Exp. No & Wall Thickness (mm) & $\begin{array}{c}\text { Infill Density } \\
(\boldsymbol{\%})\end{array}$ & $\begin{array}{c}\text { Print Speed } \\
(\mathbf{\%})\end{array}$ & $\begin{array}{c}\text { Nozzle Temperature } \\
\left({ }^{\circ} \mathbf{C}\right)\end{array}$ & $\begin{array}{c}\text { Surface Roughness } \\
(\boldsymbol{\mu m})\end{array}$ & S/N Ratio \\
\hline 1 & 0.8 & 0 & 20 & 190 & 4.12 & -12.368 \\
\hline 2 & 0.8 & 50 & 60 & 210 & 5.42 & -14.66 \\
\hline 3 & 0.8 & 100 & 100 & 230 & 6.23 & -15.888 \\
\hline 4 & 1.2 & 0 & 60 & 230 & 1.24 & -7.004 \\
\hline 5 & 1.2 & 50 & 100 & 190 & 7.16 & -4.402 \\
\hline 6 & 1.2 & 100 & 20 & 210 & 5.46 & -17.336 \\
\hline 7 & 1.6 & 0 & 100 & 210 & 1.54 & -14.74 \\
\hline 8 & 1.6 & 50 & 20 & 230 & 3.72 & -3.75 \\
\hline 9 & 1.6 & 100 & 60 & 190 & & -11.41 \\
\hline
\end{tabular}

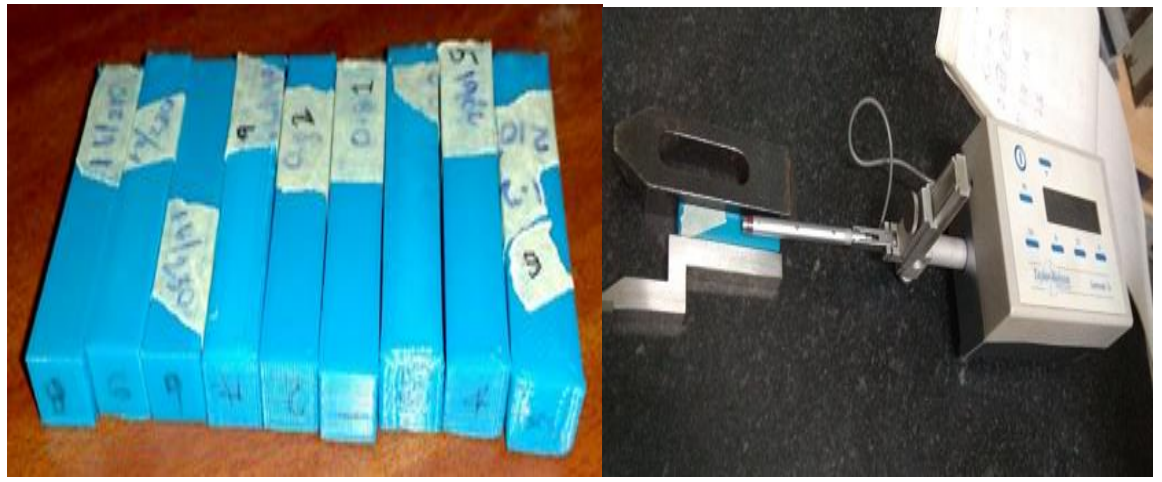

Figure 4: 3D Printed Samples $\quad$ Figure 5: Surface Roughness Tester.

Table 4: ANOVA Result

\begin{tabular}{|l|c|c|c|c|c|}
\hline \multicolumn{1}{|c|}{ Factors } & DOF & Sum of Squares & $\begin{array}{c}\text { Mean } \\
\text { Squares }\end{array}$ & F value & Contribution percentage \\
\hline Wall thickness & 2 & 41.2681 & 20.935 & 6.2057 & 20.1507 \\
\hline Infill density & 2 & 69.400 & 34.7 & 10.4360 & 33.8872 \\
\hline Print speed & 2 & 0.717 & 0.35 & 0.1052 & 0.3507 \\
\hline Nozzle temperature & 2 & 73.4466 & 36.72 & 11.0436 & 35.8632 \\
\hline Error & 6 & 19.95 & 3.325 & & 9.7488 \\
\hline Total & 8 & 204.7966 & & & 100 \\
\hline
\end{tabular}

\section{RESULTS AND DISCUSSIONS}

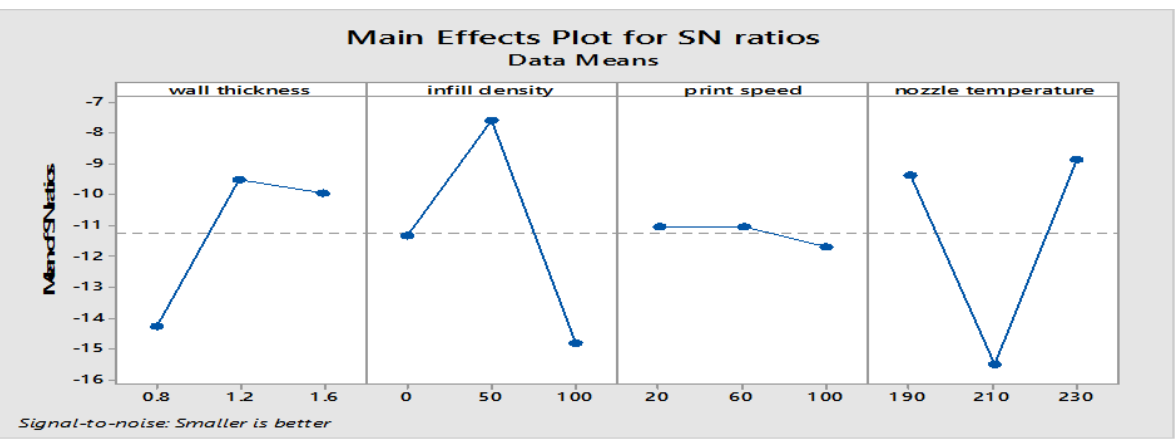

Figure 6: Main Effects Plot for Signal to Noiseratio.

This figure will evaluate the main effects of each factor for various conditions. According to this figure surface roughness will decrease with major parameters wall thickness, infill density, print speed, nozzle temperature. The surface roughness will be minimum in case of wall thickness $(1.2 \mathrm{~mm})$, infill density $(50 \%)$, print speed $(50 \%)$, nozzle temperature 
$\left(230^{\circ} \mathrm{c}\right)$, sooptimal parameter setting for surface roughness is shown below

Table 5: Optimal Values if Parameters

\begin{tabular}{|l|c|c|}
\hline \multicolumn{1}{|c|}{ Parameters } & Level & Actual value \\
\hline Wall thickness & 2 & $1.2 \mathrm{~mm}$ \\
\hline Infill Density & 2 & $50 \%$ \\
\hline Print speed & 2 & $60 \%$ \\
\hline Nozzle temperature & 3 & $230^{\circ} \mathrm{C}$ \\
\hline
\end{tabular}

\subsection{ANOVA Results for Taguchi}

From the ANOVA test its observed that the experimental error is 9.7488 , which is well below the 5\%. f calculated values revealed that nozzle temperature, infill density and wall thickness played a significant role on surface roughness. Nozzle temperature $35.8632 \%$ and infill density $33.82 \%$ and wall thickness $20.152 \%$ affects the surface roughness.

\section{CONCLUSIONS}

In the experimentation with PLA, the taguchi optimization approach was successfully tested to determine the optimal level of printing parameters on surface roughness. The parameters of the $3 \mathrm{D}$ printing process were analyzed to obtain optimum results. Based on our analysis, nozzle temperature and infill density and wall thickness are exerting a strong influence on the final surface roughness of the prints. The other parameter which is print speed did not significantly affect the surface roughness. Finally, by tuning the parameters appropriately we obtain smooth surface finish products.

\section{REFERENCES}

1. Tofail, S. A., Koumoulos, E. P., Bandyopadhyay, A., Bose, S., O’Donoghue, L., \& Charitidis, C. (2018). Additive manufacturing: scientific and technological challenges, market uptake and opportunities. Materials today, 21(1), 22-37.

2. Tran, N. H., Nguyen, V. N., Ngo, A. V., \& Nguyen, V. C. (2017). Study on the effect of fused deposition modeling (FDM) process parameters on the printed part quality. Int J Eng Res Appl, 7, 71-77.

3. Negi, S., Dhiman, S., \& Sharma, R. K. (2013). Basics, applications and future of additive manufacturing technologies: A review. Journal of Manufacturing Technology Research, 5(1/2), 75.

4. Tontowi, A. E., Ramdani, L., Erdizon, R. V., \& Baroroh, D. K. (2017). Optimization of 3D-printer process parameters for improving quality of polylactic acid printed part. International Journal of Engineering and Technology (IJET), 9(2), 589-600.

5. Sukindar, Nor Aiman. (2017). Optimization of the Parameters for Surface Quality of the Open-source 3D Printing. Journal of Mechanical Engineering. SI3. 33-43.

6. Stan, F., Stanciu, N. V., Sandu, I. L., Fetecău, C., \& Şerban, A. Effect of low and extreme-low temperature on mechanical properties of 3d-printed polyethylene terephthalate glycol. innovation, 11, 12.

7. Venkatasubbareddy, O. Y., Siddikali, P., \& Saleem, S. M. (2016). Improving the dimensional accuracy and surface roughness of FDM parts using optimization techniques. IOSR Journal of Mechanical and Civil Engineering, 16(053), 18-22.

8. Sukindar, N. A. B., Ariffin, M. K. A. B., Baharudin, B. T. H. T., Jaafar, C. N. A. B., \& Ismail, M. I. S. B. (2017). Analysis on the impact process parameters on tensile strength using $3 d$ printer repetier-host software. ARPN Journal of Engineering and Applied Sciences, 12(10), 3341-3346. 
